\title{
A Model of Collaborative Knowledge-Building Based on Web2.0
}

\author{
Rong Wang ${ }^{1,2}$, Meiqi Fang ${ }^{1}$ and Yu Chen ${ }^{1}$ \\ 'School of Information, Renmin University of China, Beijing 100872, P.R. China \\ rong@ruc.edu.cn meiqif@gmail.com yuchen318@gmail.com \\ ${ }^{2}$ Key Laboratory of Information Management and Information Economics, Ministry of \\ Education P.R.China, Beijing 100876, P.R. China rong@ruc.edu.cn
}

\begin{abstract}
The ubiquitous linking of computers in local and global networks makes possible the sharing of thoughts by people who are separated spatially or temporally. Many efforts are made to increase opportunities for effective collaborative working, learning and acting tbrough innovative uses of computer technology, and one of these efforts is to build group knowledge collaboratively. This paper presents a model of collaborative knowledgebuilding $(\mathrm{CKB})$ as a social process, which constitutes both personal and social knowledge-building as well as aggregations between them. This model incorporates insights from Web 2.0, CAS and CSCL (Computer Support of Collaborative of Learning) in the hope of providing a useful conceptual framework for the design of collaborative knowledge-building environments.
\end{abstract}

Keywords: Web2.0, Knowledge-building, Social software, Collaborative learning

\section{INTRODUCTION}

Collaborative knowledge-building (CKB) refers to active processes of constructing group sharing understandings of knowledge, which involves one's contributions to others and the use of the contributions from others. There are many research work related to $\mathrm{CKB}$. The concept of $\mathrm{CKB}$ was introduced by Scardamalia and Bereiter [1], in which authors proposed that schools should function as knowledge building communities. Some researches [2] focused on analyzing learning outcomes, some focused on understanding the processes involved in CKB [3], some focused on the development of shared understanding[4,5] of knowledge building, etc.. Singh, Hawkins, and Whymark [6] gave a general review of research work which is related to $\mathrm{CKB}$, they proposed that current studies in collaborative knowledge building (CKB) concentrate on the processes involved in group of participant's coming together to learn and create knowledge.

Current computer supported learning environments do not adequately support the collaborative nature of learning or the evolution of knowledge building within group of learning [7], but the recent emergence of Web 2.0 [8] and social software is leading to a new idea of learning environments in light of new developments in the science of learning. 
It is important to support collaborative knowledge building in learning environments. Stahl presented a model of CBK [4], which incorporated multiple distinguishable phases that constitute cycles of personal and social knowledge building. Singh, Hawkins and Whymark [6] integrated the model described by Stahl [4] with an analysis based on the principles of cultural historical activity theory (CHAT), using the analysis of a self reflective case study to guide the description. In this paper, using the two models mentioned above $[4,6]$ as a start point, we present a model based on Web2.0, and try to describe forms of computer support for phases of knowledge building according to the web 2.0 technologies.

The paper is organized as follows. We first give some preliminaries in section 2 , in which we will describe the models proposed by Stahl [4] and Singh, Hawkins \& Whymark [6]. In section 3, we discuss the opportunities provided by Web 2.0. We present a model in section 4 and describe the computer support for the model. At last we give our conclusions.

\section{PRELIMINARIES}

\section{2.l Stahl's Model}

Stahl's model [4] presents a number of important phases in collaborative knowledge building, which includes a cycle of personal understanding and a cycle of social knowledge building. In [4], Stahl described his idea of how computer system supporting the knowledge-building process.

\subsection{Singh, Hawkins and Whymark's Model}

Singh, Hawkins and Whymark's model [6] adapted from Stahl's model. It is different from Stahl's model in two aspects. First is at the individual level which using reflective thinking as a tool to develop reflective conceptual artifacts. Second is at the group level, which adopted shared work-space as common medium for individuals to interact with each other and collaborative reflective discourse as a tool for developing shared understanding.

\section{OPPORTUNITIES PROVIDED BY WEB 2.0}

Each of above models wants to provide a useful conceptual framework for the design of computer supported environment for learning or knowledge creating. By defining a sequence of typical phases of social knowledge building, the two models suggested a set of focal points where computer support may be desirable. 
The recent emergence of Web 2.0 [8] and social software with characteristics of sharing, opening, collective intelligence and everyone-involved, etc. provide us a new idea of how to support collaborative knowledge building by computer and the Web.

Blog, Social Bookmarks, Social Networking Service, and Wiki are the four main kinds of Social Software [9] which are recognized as applications of Web 2.0. Though there is no common answer to what is Web 2.0, there are more and more Web 2.0 applications on the Internet. From the view of CAS (Complex Adaptive System) theory, we think Web 2.0 has characteristics of aggregation, nonlinearity, flows and diversity, mechanisms of tagging, internal model and building blocks [10]. These characteristics and mechanisms are recognized by Holland [11] as the seven basic points of CAS.

In [10], we explain why we think Web 2.0 has these four characteristics and three mechanisms. With Web 1.0, the contents of the Web are controlled by Web site creators and users usually can only read the contents. With Web 2.0, users are the creators as well as readers. As users contribute to the Web, contents can be aggregated from these contributions automatically to form new contents with the participation of user. Even the site maintainer can not expect what contents will include in the pages. They are emergence of the activities of all participants.

\section{A CKB MODEL BASED ON WEB 2.0}

According to the Singh, Hawkins \& Whymark's model and the Stahl's model, we present an adapted model which takes Web 2.0, CAS and CSCL (Computer Support of Collaborative of Learning) into account as shown in Figure 1.

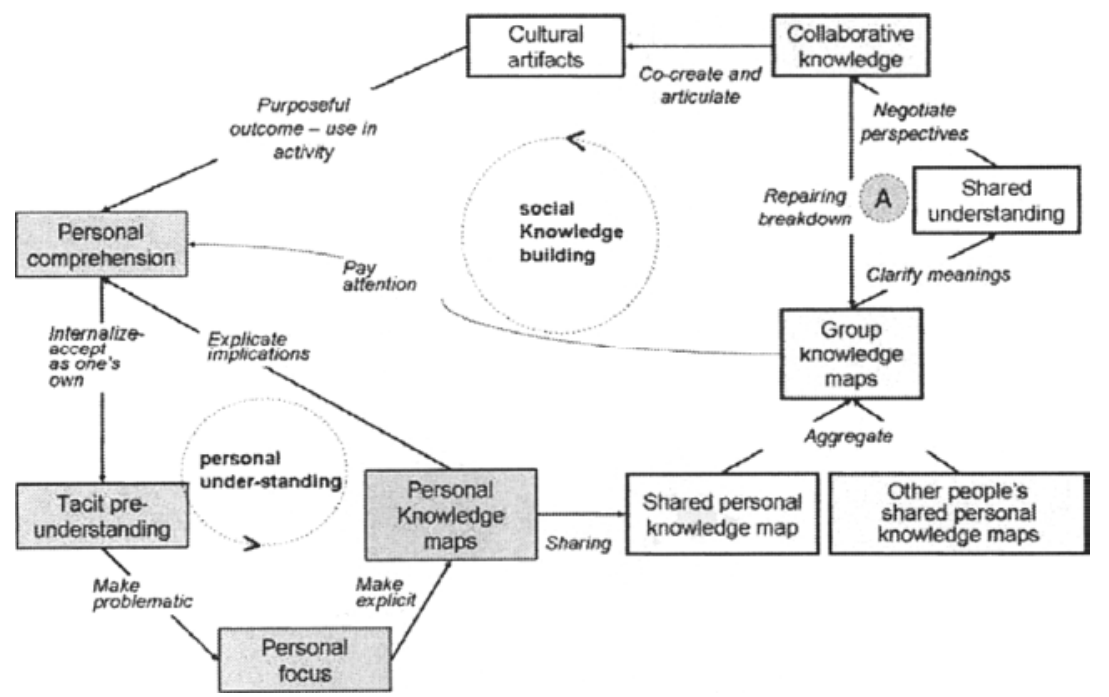

Figure 1. A CKB Model Based on Web 2.0 
The convention in the diagram is that arrows represent transformative processes and that rectangles represent the products of these processes: forms of knowledge. The model includes a cycle of personal understanding that is focusing at the individual level and a cycle of social knowledge building that is focusing at the group level. We adopt knowledge map which is different from Stahl's [4] and Singh's [6] model. When faced with a problematic situation (or learning new knowledge), an individual focus on the problem and make meaning explicit by knowledge map which can provide a common form of shared understanding and collaboratively build knowledge. Knowledge map can be any facilitate tool that can represent the map of knowledge, such as concept map. To communicate with other people, an individual can share the whole or part of his knowledge map on the Internet.

In social knowledge building cycle, all shared knowledge maps will be aggregated into a big group knowledge map through some mechanism, and then the group engages in discussion, voting and other interacting methods to develop shared understanding. Even though cycles 1 and 2 are shown as separable, they are intertwined at Figure 1. From the perspective of social interactions, there is an expectation of constructive response to one another's work.

Computer support for knowledge map can be varies forms, but it should facilitate the process of articulating ideas and preserving in them in convenient forms. There are many developed tools that can be used to create knowledge map, such as mind manager which can export maps drawn by it in XML and import information as topics or subtopics from Web's RSS feeds. Knowledge map can stored on the personal computer or on the Web. Nodes in knowledge map can be regarded as tags of related resource on the Internet.

If an individual want to share his knowledge maps with others, he can contribute his knowledge maps in XML on the Web. If one interested in some topics of arrogated knowledge maps, he can subscribe them by RSS.

To aggregate different individuals' knowledge maps into a big one maybe is one of the most difficult tasks which need optimized algorithms.

As to the small collaborative cycle of $\mathrm{A}$, it can be fostered by various mechanisms. For example, if one agrees with a topic or relation in the knowledge map, he can vote it or he can reject it, if a topic appears in many people's knowledge maps, then it is a hot topic, if a tag refers to different resources, it means these resources have some relation in some sense, etc.

\section{CONCLUSIONS AND FUTURE WORKS}

In this paper, we present a collaborative knowledge building model based on Stahl's and Singh, Hawkins \& Whymark's model, and describe computer support for the phases of the model. Our future work is to develop a sample system which can support or partly support this kind of model. Collaborative knowledge building is a complex process, it can not support by a pre-defined system, so we should provide four characteristics and three mechanisms of CAS. 


\section{ACKNOWLEDGMENTS}

This work is supported by Open Foundation of Key Laboratory of Information Management and Information Economics, Ministry of Education P.R.C, Grant \#F0607-16 and National Social Science Foundation of P.R. China, Grant \#06BTQ016.

\section{REFERENCES}

1. M. Cardamalia and C. Bereiter, Computer Support for Knowledge-Building Communities, The Journal of the Learning Sciences. Volume 3, Number 3, pp.265-283, (1994).

2. S. Paavola, L. Lipponen, and K. Hakkarainen, Epistemological Foundations for CSCL: A Comparison of Three Models of Innovative Knowledge Communities, in Proc. of Computer supported collaborative learning: Foundations for a CSCL community: Proceedings of the Computer-Supported Collaborative Learning 2002 conference, eds. G. Stahl (Lawrence Erlbaum: Hillsdale, NJ, 2002), pp.24-32.

3. P. Dillenbourg, M. Baker, A. Blaye, and C. O'Malley, The Evolution of Research on Collaborative Learning, in Learning in humans and machine: Towards an interdisciplinary learning science, eds. E. Spada and P. Reiman (Elsevir: Oxford, 2006), pp.189-211.

4. G. Stahl and G. Cognition, Computer Support for Building Collaborative Knowledge (MIT Press: Cambridge MA, 2006).

5. J. Yukawa, Co-reflection in online learning: Collaborative critical thinking as narrative, International Joumal of Computer-Supported Collaborative Learning. Volume 1, Number 2, pp.203-228, (2006).

6. G. Singh, L. Hawkins, and G. Whymark, An Integrated Model of Collaborative Knowledge Building, Interdisciplinary Journal of Knowledge and Learning Objects. Volume 3, pp.85-105, (2007).

7. R. Wang, M. Fang, and Y. Chen, Research of Social Group Collaborative Learning, Management Sciences in China. Volume 20, pp.80-83, (2007).

8. T. O'Reilly, What Is Web 2.0 -- Design Patterns and Business Models for the Next Generation of Software, O'Reilly Media, Inc. (2007). http://www.oreillynet.com/pub/a/oreilly/tim/news/2005/09/30/what-is-web-20.html (Accessed July 14, 2007).

9. S. Zhang, Study from Social Software, Web2.0 to Complex Adaptive Information System. Ph.D Thesis, Renmin University of China (2006).

10. W. Yuan, Y. Chen, and R. Wang, Collective Intelligence from the View of the Internet, in Proc. of The IFIP TC8 International Conference on Research and Practical Issues of Enterprise Information Systems (Beijing, forthcoming, 2007).

11. J.H. Holland, Hidden Order: How Adaptation Builds Complexity (Addison-Wesley: Massachusetts, 1995). 